\title{
Introduction: examining the politics of transparency
}

\section{Christina Garsten and Monica Lindh de Montoya}

Transparency is a concept that has gained increasing currency and favour as an organizing principle and administrative goal in recent years. We note calls for greater transparency directed towards states, markets and corporations, in civil service, in local and national political processes, and in regard to large agglomerating institutions such as the European Union and the World Trade Organization. In a wide variety of situations the idea of transparency is held up as a panacea for the ills that a concentration of power can imply; a way in which citizens can attain a level of justice and control vis-à-vis institutions that affect their lives. We observe transparency in organizational policy, not least in relation to discussions of democracy and electoral procedures. It is invoked in fights against corruption and bribery, and in efforts to promote 'good governance'. In the financial world, transparency is closely linked to pressures for more open and just accounting and auditing procedures. Transparency is also invoked more generally by protective state agencies as a set of technologies that promise to render life safer for ordinary people by close monitoring of risky elements, human and other. We observe transparency not only in organizations, but also more widely in our changing material world - in architecture, design and fashion. Clothing becomes more and more revealing, transparent social life 'on exhibit' is celebrated in endless reality shows and revealing documentaries are praised - subtlety and fiction take a back seat to 'what's really happening'.

The call for transparency intensifies at a time when the modern nationstate is faced with the challenge of governing financial flows of capital, cultural influences and organizational impacts. Transparency runs alongside attempts to organize and control beyond local and cultural particularities. It suggests that visibility, information and openness are closely linked with organizing, and that what is visible can also be represented, objectified, measured and compared. One of the prerogatives of late capitalism, it seems, is making the world hospitable for translocal, universal forms of administration and governance and this entails making the world legible and transparent. As James C. Scott (1998) has shown for the development 
of the modern state, a central project from the outset was to make society more 'legible'. Legibility, Scott argues, was part and parcel of the postEnlightenment process of 'the administrative ordering of nature and society' and the story of the inexorable growth of state power (Scott, 1998, p. 83). That citizens, communities, corporations could be read, distinguished, seen, indeed made transparent, was central for the making of the modern state. It would seem that this is even more central today, with global governance being one of the daunting challenges on the political agenda. In a recent significant volume edited by Hood and Heald (2007), the widespread nostrum of 'good governance' is placed under critical scrutiny, as they trace out the history of transparency and related doctrines in government and public policy. 'Like many other notions of a quasi-religious nature, transparency is more often preached than practiced, more often invoked than defined, and indeed might ironically be said to be mystic in essence, at least to some extent', it is argued (Hood, 2007, p. 1). Yet, the doctrine of transparency has been put forward as a means to make the state and its inhabitants more 'knowable' and 'governable', a process that involves some tricky trade-offs and balancing acts. Transparency, then, is an entry-point to the understanding of contemporary society and culture and the power-games that are played out in attempting to organize it.

Yet few attempts have been made to examine the actual content and playing-out of transparency, such as, for example, the complex negotiations through which it is determined what shall be displayed and what shall remain hidden, how power and control enter into the practices of transparency and the processes through which transparency is (or is not) achieved. How is the concept interpreted, practised, emulated, inverted or used to achieve particular ends?

This volume explores the ideas and practices of transparency in different social and organizational contexts, with the hope of instigating a discussion of the strengths, limitations, ambiguities and many facets of the term. We aim to shed light on this powerful global discourse and the practices around the concept of transparency by opening up the concept for illumination from a broad, anthropological perspective. In this, we hope to contribute to an understanding of the wider organizational, cultural and ideational context in which transparency is used and put to work. It will allow us to assess in what respects and to what extent the global discourse, as well as the practice, of transparency is actually transforming business and governmental practices, social relations and ways of thinking about these. Moreover, we wish to point to ways in which notions of transparency are involved in efforts to fashion, govern and control the whereabouts of people, and ways in which people circumvent them. In our view, transparency is part and parcel of a nexus of associated ideas that together make up the new, 
globalized market rationality in contemporary society. It is suggestive of the challenges of organizing society in a period of intense globalization of capital and culture. More specifically, we suggest, transparency is closely linked to a neoliberal ethos of governance that promotes individualism, entrepreneurship, voluntary forms of regulation and formalized types of accountability. It is powerful in that it is inscribed in political, financial and cultural documents, processes and policies that not only suggest, but push for, a certain normative order.

Most of the chapters in the volume discuss ethnographic cases and are tightly focused on illuminating processes aimed at achieving transparency. They cover several sectors, including corporate visions, European policymaking, the new military, financial markets, education and architecture. Together, they provide a diversity of ethnographic material and a wide scope of analysis. Our ambition throughout has been to reveal the connection between the global discourse and local practices of transparency and to contribute to the discussion of the concepts, models and metaphors that guide and shape organizational, social and aesthetical practices today. We believe the volume's primary interest lies in the empirical richness of local case studies and the way in which these are related to wider policy aims, ideological shifts and the discursive dynamics of influential organizations.

\section{VISIBILITY, OPENNESS - AND A 'CULTURE OF MISTRUST"}

Much of the potential and power of the idea of transparency in organizational life is related to its power as a mechanism for visibility and revelation. So much in human life is charged with the energy that feeds off the tension between the known and the unknown, and is communicated to us though unquestioned practices that are deeply embedded in our social lives. From our earliest years we are taught about concealment, we are taught to clothe ourselves, play peek-a-boo and then hide and seek. We are taught that we must tell the truth, but discover that social fibs are both tolerated and necessary. As we grow older we gradually learn what information is best withheld from parents, teachers, employers, friends. We form groups, we learn the importance of revealing and withholding information for belonging and for drawing boundaries of inclusion and exclusion. We learn to present ourselves, devising self-images that are a compromise of what we think we are, and what we would like to be. Some things are kept as skeletons in the cupboard, as it were. In order to remain viable social beings, we need to provide a reasonable degree of transparency to those around us, an 
accounting of who and what we are; and we do so through, for example, curricula vitae (CVs) and resumés, work histories and the life histories we tell friends and acquaintances. Our friends and associates also help us do the job, through the mechanisms of anecdote and gossip.

Transparency implies visibility, openness and communication. It is a metaphorical extension of its meaning in the physical sciences: a 'transparent' object is one that can be seen through. 'Seeing through', however, is always a matter of position and of degree. Quoting Bauman (1998, p. 29), '[w] hat is easily legible and transparent for some, can be dark and opaque for others'. And herein lies the power of transparency as an organizational vision; it can be played with, negotiated and temporarily agreed upon. Vision, seeing and seeing through, as Heidegger would have put it, is a way of engaging with the world. And as such, transparency may in our reading be understood as 'a gaze' moved by a particular 'circumspective concern' (Heidegger, 1982, p. 176). In a much related manner of thinking, David Michael Levin in his intriguing volume The Opening of Vision (1988) has traced certain aspects of contemporary Western society and culture to our concrete historical experience with vision. From discussions of egocentric vision in everyday life, the world-view of science, the political economy of modern technology and the paradigm of vision in metaphysics, he draws on the Frankfurt School and Foucault to demonstrate that many of the sufferings, the needs and the injustices of our world are connected to vision, to particular ways of seeing and the patriarchal will to power. ${ }^{1}$

Transparency is about visibility, about the flow of information in the numerous relationships established between citizens, the citizen and the state, the citizen and the economy in which he or she makes a living. Transparency has often been linked to totalitarian regimes, implying monitoring and control by way of repressive technologies. ${ }^{2}$ In its present version, it is instead tightly interlinked with the practice of democracy and with neoliberalism, and with a cluster of ideas that have gained increased currency since the beginning of the 1990s and the end of the Cold War, that point towards a certain way of organizing society that emphasizes the individual as the basic constitutive active agent in the construction of his or her fate and of societyat-large. In such a vision of social life, the transactions between citizens and the state and within the economy must be open and observable in the interests of maintaining a level playing field for all concerned. In processes of globalization of markets, tightened economic competition and a fragmented political authority, such ideas gain increased momentum. Thus the calls for transparency grow and spread across the globe. What is notable (in each system of power that has taken transparency on board, we may add) is, in Zygmunt Bauman's words (1998, p. 33), 'the positing of transparency and legibility as a goal to be politically pursued - a task; something which still 
needs to be enforced on recalcitrant reality, having first been carefully designed with the help of specialists' expertise'.

Information is the crucial component of transparency processes. Governments and their institutions must provide reliable information in order to be considered transparent in their intentions, their policies and in the implementation of these. Publicly disseminated audits of performance support policies and serve as a measure of how well intentions are put into practice. Through consultation with different stakeholders, government institutions and non-governmental organizations (NGOs) can also involve the public, benefiting from their time and input, and providing greater visibility into public processes (Strathern, 2005). The economic sector is equally subject to demands for transparency. Private or publicly held companies are examined for their economic practices regarding labour, accounting, information to shareholders, their economic worth. Their goods and services are examined for safety and for adherence to various standards which are not uncommonly the product of so-called 'soft law', or voluntary regulations. Many goods bear a series of labels indicating compliance with both national and international regulations. Keywords associated with transparency, then, are stakeholders, policy, audit, visibility, accountability, compliance, regulation, governance. Others that might be added are equality, fairness, individuality, responsibility, integrity.

Transparency is appearing in a number of other likely and unlikely areas of our lives. One is in the sphere of the workplace, with glass buildings, open-plan offices and various fora for communication in the workplace. Increasingly, companies and business schools are adopting software solutions that openly reveal each individual employee's calendar and whereabouts. At universities, we are being drawn into procedural exercises aimed at making visible, and scrutinizing our 'outputs' in terms of international publications in high-ranking journals and number of students passed, as well as formalizing and making our policies and administrative routines auditable. The European Bologna educational reform focuses on implementing transparent, comparable educational systems within the European Union (EU) member states, and courses are designed to be transparent regarding content, goals and examination criteria, allowing students to better evaluate what they sign up for and holding teachers accountable (cf. Strathern, 2000). Homes also are becoming more open, with social areas integrated with the kitchen where the family spends much of its time, as are products - see-through watches and appliances, storage boxes and closets. Another arena is between the individual and society, with exhortations to 'be yourself' and show your 'own style', in short to perform one's personality - and consumption is also to an increasing degree becoming a way of manifesting a political persona, through the choice of particular goods and 
services, and not others. Relationships between people should also be open and visible; there should be no deception between friends and colleagues, no lies between couples. The concept of transparency can thus be seen to be embedded in a particular view of the capacities and possibilities of the individual and society that have wider repercussions in cultural life. These developments also show that transparency is a relational thing, to do with communication, and it involves a specific relation between the one who is seeing and the one who is being seen.

Despite the apparent urge towards openness and disclosure, all is not so simple. Human life, the daily life of individuals as well as the public life of governments, companies and organizations, is full of secrets and ambiguities, of that which can be said and that which cannot. Governments and institutions darken certain problematic issues to keep a tight hold on power and to hide deficiencies; companies find ever-changing ways to evade controls and responsibilities - the Enron and Tyco scandals occurred despite the strict controls exercised over companies even then. Revelation is always incomplete; and is open to all manner of interpretation and negotiation. The prerogative of power is a force to be reckoned with. Despite all the 'mutual veil-dropping' that has occurred since the end of the Cold War era, from the perspective of the less privileged, of those lacking access to information, the operation of power often appears opaque and unpredictable (see West and Sanders, 2003, for an important contribution on the relation of transparency to conspiracy, suspicion and power in contemporary globality).

Several scholars have noted that transparency is linked to games of power and control. Ever since (and quite probably also before) Jeremy Bentham's Panopticon appeared in 1791, the all-seeing eye has been brought into discussions on the nature of power and ways of exercising control. ${ }^{3}$ Bentham's basic idea was that, through careful architectural design, the whereabouts of every single prisoner in the new prison could be constantly observed by the prison guards. The design would allow the observer to observe without the prisoners being aware of it, thus creating a 'sentiment of an invisible omniscience'. The awareness of being seen would also contribute to a self-disciplining on the part of prisoners. The idea was that this model was to be widely used, in schools, hospitals and factories, where people needed to be managed and to some extent controlled. The self-disciplining implications of constantly being seen would allow for an efficient and cost-effective system of control. This utopian, rational vision of the mouldable human being and the transparent society was never a great success in practice, but the ideas were picked up by early management theorists, planners and policy-makers, as well as academic scholars.

The idea of the panopticon is most widely known through the work of Michel Foucault (in particular Discipline and Punish, 1977), who viewed 
panopticon as a political technology in the abstract, with wide applicability and far-reaching consequences. ${ }^{4}$ The idea was central in his discussions of modern disciplinary societies and tendencies for close observation and normalization. The logic was one of surveillance, enshrined in institutions such as the factory, the hospital inspection, the school examination and the military review (Graeber, 2001, p. 95). Interestingly, with regard to 'vision', while power in the feudal system was 'what was seen', by way of visual representations in cathedrals, palaces and in the material body of the king (Foucault, 1977, p. 187), power has now assumed a faceless character, 'exercised by faceless, invisible bureaucracies that inspect, examine, and evaluate their objects' (Graeber, 2001, p. 95). The notions of panopticon and of transparency are here intricately linked with new forms of disciplinary power and control, involving a process of universally applicable administrative technologies and of disciplining the self. In a foucauldian reading, transparency is thus vital to neoliberal 'governmentality', that is, forms of control in which power is decentred and in which individuals play an active role in their own self-government, and to the games of power that are being played out in contemporary society.

In relation to 'audit society', or 'audit culture', transparency signifies that we are living in a 'culture of mistrust'. As pointed out by Michael Power (1997), audit is itself a 'technology of mistrust', designed in the hope of restoring trust in organizations and professionals. Transparency, as well as accountability, here becomes a symbol of organizational trust and health (see Rose, 1999, pp. 154-5). The more we see, the more we know, it would seem, and the more we can place our trust in the expertise and professionalism of organizations. The more 'evidence' we can gather of what goes on, the more of factual verification we can get hold of, the more forcefully we can argue our case. Yet, one may wonder whether such measures do not in fact serve to amplify a sense of insecurity and mistrust, rather than to ease uncertainty and restore trust. There is no obvious end to the call for more transparency.

The eye of power also follows us through measures of monitoring and of surveillance. We need only think about the many technologies used to monitor our daily actions to realize the extent to which some sort of surveillance is being exercised on our orbits: surveillance cameras in the streets, performance evaluation schemes, medical screening, airport security screening and the like. A telling example is London's 'ring of steel', the security and surveillance cordon of closed-circuit television (CCTV) cameras and other technological devices surrounding the city, installed to deter potential terrorists and others who threaten law and order. And, we may recall the enhanced screening procedures at international airports, with ever more sophisticated means of making us and our belongings transparent (not to mention making travelling more troublesome and time-consuming). 
Scholars like Gilles Deleuze have taken Foucault's argument on 'disciplinary society' further, suggesting that a new diagram of control has taken place, in which the control of conduct is now immanent to all the places in which actors move about, inscribed in the very dynamics of social practices (Deleuze, 1995). 'Control society' entails a continual monitoring and reshaping in all networks of practice, not just surveillance of individuals in particular sites. It means a never-ending process of modulation of the capacities and practices of the human being. We are always on continuous training, lifelong learning, perpetual assessment, continual incitement to buy, to improve ourselves, and continuously monitoring our health, and engaged in continuous risk-management (or, at least we ought to be). Monitoring technologies seem to be all over the place, invading our everyday lives. In Rose's words, 'Control is not centralized but dispersed; it flows through a network of open circuits that are rhizomatic and not hierarchical' (Rose, 1999, p. 234).

Evidently, the pursuit of transparency involves as well a reliance on knowledge, science and expertise. The visibility of 'facts', the legibility of social life and the measurability of organizational performance rely on the mediation of experts. According to a number of scholars, most notably Anthony Giddens (1990), expert systems of knowledge and of trustworthiness are intrinsic to late modernity. This requires open and reflexive relations between expert systems, their representatives and lay people. Central in these encounters are 'access points' that are able to generate a degree of assurance (as in the case of the air stewardess) and a 'business as usual mentality' in circumstances where there is risk. These access points, while reembedding the distantiated character of social life, characteristically draw upon a non-transparent expert knowledge base where various information is withheld from public inspection. Trust is necessitated by ignorance or lack of a transparency into complex and abstract technological systems. The pursuit of transparency as an organizational vision thus leans heavily on the access points between experts and lay people, and on how transparency is negotiated at these very intersections.

As careful observers of social interaction, anthropologists and sociologists are well placed to document and deconstruct the production of transparency. The matter of what constitutes transparency is a subject of negotiation: between individuals, within organizations, between organizations and the state, organizations and the public. By nature an unfinished process, it is always tentative and ongoing. As the chapters in this volume testify, there is no formula; what is and what is not sufficiently transparent is situational, a result of what is demanded and what can be offered. What should be noted is that the production of transparency involves costs, in time and patience and in compromises, as well as concrete material costs. It also demands a public able to consume it - an educated, interested 
and involved public that can evaluate what is offered and enter into the negotiations.

\section{TRANSPARENCY AND UTOPIA: VISIBILITY, TRUTH, FUTURE}

If transparency is a vision for the future, what are its characteristics? How is it played out in different versions of contemporary society? The chapters in Part I point out that achieving transparency is a complicated endeavour. What is presented is always a subject of interpretation, be it by those who create it or those who consume it. Moreover, it is a subject of negotiation and of contestation, involving continuous games of definition.

Olesen's chapter (Chapter 1) focuses on a central problem in the concept of transparency. Departing from Roland Barthes's (1967) 'transparency effect', Olesen notes that facts do not exist as such before there is a narrative framework to establish their significance - facts take on meaning only in the context of narratives. Anything that has happened, then, has necessarily happened from the communicator's point of view, and 'facts' only exist as linguistic artefacts. The anonymous, impersonal style of conventional historical discourse hides narrative, however, creating the illusion that historiographical representations appear to be simple copies of a 'real' existence. As Barthes indicates, the representational genres developed in Western civilization such as news items, documentary literature, historical museums, diaries, realistic novels and especially the spread of photography hide the nature of the relationship between past reality and its representation, making 'the transparency effect' a basic characteristic of our societies. Here, then, is a basic characteristic of transparency: although it intends to reveal, it can only produce situated revelations, and will only tell one of many 'stories'.

In her discussion of the United States Holocaust Memorial Museum, Olesen describes the interior of the museum, indicating that much of the representation of the Holocaust depends on artefacts closely tied to this 'transparency effect' - reproductions, such as photographs enlarged to life size, and photographs of prisoners including their life stories (very palpable narratives) as well as actual objects from the concentration camps themselves, such as old shoes and an entry portal. It is the sometimes intense controversy over the history of the Holocaust that has made the designers of the museum embrace the strategy of presenting only 'facts' - representations of people and places, as well as actual objects - and letting them speak for themselves. But even in this setting forth of history, Olesen notes, conflicts and debates are submerged; and in 'sticking only to the facts' the museum faces other limitations. For example, the problems involved in 
using the available facts to establish a definite historical interpretation are not presented or discussed, diminishing understanding of the complexities of history. The lack of such discussions also highlight the strength of 'the transparency effect' that the museum produces.

Timm's contribution to this volume (Chapter 2) discusses transparency not as a production, but as a practical enactment within another, quite different structure - a Swedish business school that was set up and financed by Sweden to support the Baltic states' transition from the Soviet era economy to the capitalist free market. The main aim of the school is to teach the ideals and practices of Western economies to high-achieving students who will make up the next generation of business people in the Baltic region. Timm sees the school as imparting a particular kind of moral force to its students, and examines the ways in which this force is concretely manifested. Transparency and openness are integral concepts throughout students' education in the school; visible in everything from the building itself to the admission procedures, open classrooms and the openness manifested between teachers and students. Open spaces, substantial amounts of freedom combined with rigorous requirements, an emphasis on teamwork, the free flow of information, diversity, tolerance and equality between students, teachers and staff are some of the elements of this, for the Baltic region, very exclusive and innovative education. Students take advantage of it in unexpected ways, however, and bend the rules to better suit the culture that they have grown up in, which does recognize status and ethnic differences. They prefer to form teams of friends and acquaintances, and accumulate informal debt and credit among themselves, participating very actively on some projects and 'freeriding' on others. The use of name tags, English only, and staff equality are elements that have been difficult for the school administration to impose. Thus, the generalized organizational ideals of transparency and equality constantly negotiate with local culture and practice, which affect outcomes. Interestingly, the students in this business school appear to have learned their lessons almost too well; Timm notes that after graduation most of them can be found working for transnational corporations, rather than contributing their vision and expertise to local companies.

If those who work within modern businesses or organizations are to exhibit particular values and practices, what about institutions and organizations as such? In what ways do they exhibit themselves, make their nature known? Certainly in modern society we see repeated examples of how organizations manifest their mission, core values and goals, 'who we are' and 'what we stand for'. The chapter by Galli (Chapter 3) approaches transparency from this direction, discussing the process through which an advertising agency acquires the knowledge it needs to work with an organization's brand to reposition it with the public and vis-à-vis its 
competitors. Such exercises are undertaken 'to answer some questions about who we are, and, more crucially, who we want to be', and involve the participation of employees who brainstorm together to come up with concrete characteristics that clarify the image that they want their organization to project. As Galli indicates, the series of exercises oblige the participants to look deeply within their organization in order to come up with descriptive categories, and then challenge them to compare and contrast their descriptions with other categories in a process which gradually distils a portrait of the organization. Interestingly, in looking within the organization, employees also look within themselves, and the target pictures that company employees come up with during such brainstorming exercises are as much a constitution of themselves and their cherished values as a desired projection. In this way, the organization is indeed forming an organizational identity, and making itself transparent, while the advertising agency functions as the active listener, gathering the material it needs to be able to produce images that will both describe the organization and resonate with its public or customers.

Transnational corporations are powerful actors in contemporary global society. Their influence on the distribution of resources - economic, social, educational, environmental - is wide-ranging. Equally evident is the challenge for state agencies to gain some degree of overview and control of the extent to which they are actually living up to national and international regulations and agreements on issues relating to human rights, workers' rights and democratic governance. The media, activist groups and nongovernmental organizations have contributed to making the global regulatory gap visible and the need for measures to increase openness, transparency and accountability in organizational processes. Within the corporate social responsibility movement (CSR), transparency occupies a central place, closely tied to accountability, and to the technologies by which these are to be implemented: voluntary codes of conduct, standards for social responsibility and the like.

Garsten and Lindh de Montoya (Chapter 4) examine the flow of information in modern corporations and the tension between incentives to conceal and imperatives to reveal at all levels of corporate life, from the leadership to the rank and file, noting that transparency is about boundary-work as well as about power. It is hardly a new problem in organizational life, but rather a classic issue in organization and management that has been pushed into the spotlight by recent corporate scandals, the growth of individuals investing in stock markets and increasing interest and advocacy in the CSR field, including the proliferation of social standards and codes of conduct. 'Being transparent' and 'accountable' are moving rapidly from being voluntary acts to becoming normative imperatives considered basic for 
establishing trust and generating profits and value. It should be recognized, however, that demands for transparency also have a coercive aspect - forced voluntariness - and involve costs, sometimes substantial ones.

\section{TRANSPARENCY AND REGULATION: NEGOTIATION, IDEALS, COMPROMISES}

Although in this volume we are arguing for a wide description of the phenomenon of transparency, and include a wide variety of manifestations of the principle in an effort to show how it is an important organizing principle for our times, transparency has without a doubt recently been most discussed in connection with economic transactions. The sudden and unexpected collapse of huge companies - Enron, Tyco, Parmalat and Scandia, to mention only a few - owing to economic practices hidden from public view caused outrage in the economic community and among the public, spurring new rounds of regulation. Several contributions in Part II discuss transparency in economic life, revealing the consultative processes by means of which transparency is constructed.

Transparency has been frequently discussed in relation to regulation, not least voluntary forms of regulation, such as soft law and codes of conduct. It is thus closely associated with governance, or governing without government, and new forms of control such as partnerships and networks. It involves a particular understanding of governance and regulation, one stressing the value of visibility, observability and revelation. In Ann Florini's words, 'Transparency may thus be discussed as regulation by revelation' (Florini, 2003, p. 34). By making information about policymaking processes, decision-making, environmental and labour practices or budgets accessible to the public, governments and corporations are forced to be responsible and trustworthy.

Also relevant to this notion of transparency is the 'trust in numbers' so widely spread in public policy-making, in the financial markets and in corporate board rooms. Belief in the neutrality of numbers has underpinned the building of welfare societies, labour market policies and measures, as well as decisions on investment and bankruptcy. The use of indicators and the like is based on the idea that numbers are politically neutral and that they are easy to compare (Miller, 2001, p. 382; Porter, 1995, p. 8), allowing for judgement of what is 'best practice' and 'good governance'. These, and similar terms, like 'good definition' and 'robust data' are presented as objective and neutral. Our take on it is rather that they are not objective entities, but reflect processes of negation and definition-drafting. Indicators, figures and numbers are produced in a political and cultural context, by actors 
with particular interests and perspectives, which have an impact on the ways they are used in regulatory activities and on the outcomes.

Noting that the concept of transparency is beginning to appear in a variety of contexts such as management, corporate governance, multilateral policy-making, banking and market efficiency, Grossman et al. (Chapter 5) explore the common elements that the concept shares in three spheres in which references to transparency are frequent - markets and price discovery, management and institutional investors, and state regulation and economic policy. By briefly examining cases within these spheres they shed light on some of the issues and contradictions involved in the provision of transparency.

A key difference in modes of transparency, they note, is that they can be either virtual or abstract. Financial markets, for instance, may be transparent either because all the actors 'see' and recognize each other, or because they do not, as is the case in modern trading systems where bids are anonymous and transactions carried out via algorithms. Thus, transparency occurs as well in environments where actors do not 'see'; the vital element is egalitarianism, monitored by an abstract entity such as a trading board or other overseer. This is an aspect of transparency that comes up again in Montoya's discussion of voting processes; without secret and hidden spaces, such as the secret vote - again monitored by an abstract entity - the exercise of democracy is impossible.

In the realm of institutional investment and corporate governance, the authors point out that format is very important in transparency, as small changes in disclosure demands and timelines can make a big difference to the diffusion of information, and the consequent ability of the public to react. They indicate that transparency involves costs, and demands a transparency-literate public. The aspect of the public in transparency-and it is very much a public phenomenon - is interesting. Transparency is a sharing, an invitation to discussion. This can be seen in action in the way multilateral organizations such as the European Commission now draft policies - with openness with and between stakeholders. Variations on this theme and various difficulties experienced in constructing transparency between government and citizens are discussed by Soneryd and by Abram. Transparency practices can either be disciplinary, that is, calling to account, or enabling, that is, setting up infrastructures which more easily allows for open practices. Literal transparency stresses individual involvement in transparency, while abstract transparency refers to aggregating mechanisms which abstract the public, and produces transparency through measurement devices.

Transparency needs devices for its implementation, and Grossman et al. make a case for viewing the phenomenon more as a set of devices than a 
principle. How transparency is put into action - whether it is disciplinary or enabling, literal or abstract - makes a great difference regarding the way and the extent to which it involves and benefits the public.

Yenkey's and Thedvall's contributions (Chapters 6 and 7), drawn from different areas of regulation, both point out the ways in which the transparency that is presented to the public is negotiated in sometimes quite lengthy and complex processes, in which self-positioning in relation to others and manoeuvring to obscure data may have as large a part to play as the need to reveal. Yenkey discusses the financial regulation of stock markets, and focuses on the activities of the Securities and Exchange Commission (SEC) over the past decades, and how these have been received by traded companies and by the public. He notes a process of negotiation that takes place between regulators and the regulated, a tug of war regarding how much information must be disclosed. While regulators, acting both on US Congress initiatives and based on their own research, tend to increase the amount of disclosure required, companies and brokerages resist, seeking to retain advantages, market niches and to limit the economic costs of the production of transparency. Thus markets are - despite the diligence of regulators - constructed and enacted by human beings and will remain imperfect. As MacKenzie et al. (2005) have noted, today's complex business enterprises are in a constant state of movement and it is very difficult to determine their precise financial situation - and the snapshots created through official documents are limited by the structure of those documents. Also, companies are in some respects able to use their discretion regarding what is divulged. Transparency can never be complete, but it moves us as a collective towards a higher state of deliberative democracy.

Another process of negotiation; but one that is more formalized, is the one discussed in Thedvall's chapter. The European Union's attempt to coordinate their labour market policies has resulted in the development of a common strategy including guidelines that are supposed to inform member states' labour market policies. A series of indicators have been developed to make policies more transparent and to monitor and assess progress within member states and between states. Thedvall takes us into the nitty-gritty negotiations taking place in committee meetings, showing how different member states react to and lobby for particular indicators, depending on the political and economic history that has shaped labour relations in their country, and what they believe should be shown. The member states sometimes have quite different opinions regarding what is important to measure, and what should be put on display. For example, are frequent strikes a measure of the engagement of the public in labour issues, or are they an indication of poor communication between employees and employers? Here, transparency is shown to be a product that is socially constructed: as 
member states negotiate about what indicators should be used to evaluate, audit and compare each other, they construct the parameters of transparency; and here, by building alliances and reaching compromises, there is room to manoeuvre, to ensure that certain aspects of labour relations are measured and others are not. While the figures that are finally published and consumed by the public may appear to be politically neutral, they are in fact neither objective nor context-free.

Hasselström also examines the selection of criteria in the production of transparency in her chapter on ethical investment funds. While a number of international organizations are active in defining socially responsible investing, there is no consensus regarding what standards should apply. Nonetheless, some generally accepted principles concerning social reporting can be established. The use of measuring instruments is central to the project of evaluating whether or not a particular company's stocks or certain financial products can be seen as being ethical, and measurement is seen to depend on transparency - that is, corporations' will to disclose information regarding their activities. Measuring tools that standardize and make comparisons possible are needed in order to grade or rank investment vehicles as more or less responsible - but what should they measure, and in what way? Hasselström (Chapter 8) discusses how different measuring tools currently in use are constructed, showing the numerous complex calculations that go into establishing rating systems that serve as vouchers for the correctness of the financial products advertised as 'ethical'. She questions the fact that the tools themselves are not discussed as problematical, although they serve to define what they measure - there seems to be an unquestioned belief that application of the proper tools will guarantee investments' social responsibility.

The above-mentioned chapters, then, discuss different ways in which transparency is mediated. It may be established by governing commissions and renegotiated by the governed, thrashed out in highly political committee meetings, or more mechanically established by academics designing measuring tools. The fact that all representation is situated, or mediated, as Klintman and Boström note (Chapter 9), seems to be a fundamental challenge in achieving transparency. In their chapter these authors, who have written widely on ecological risk and eco-labelling, develop a framework for thinking about different levels, or layers of transparency or transparency processes. They note four layers, of which mediated transparency is the simplest; here, the public puts its faith in the measuring devices of the groups of experts who set up labelling schemes. The next level, negotiated transparency, pays attention to the interdependence and inseparability of 'substantial' or material factors such as criteria, substances, thresholds and so on, and the labelling procedure itself - the political framework, and the 
goals and strategies of different actors which all have consequences for the process of constructing a transparent labelling scheme. Discussion of criteria and trade-offs are inevitable in any regulation process, yet this is seldom apparent in the labels that customers see. The third level, intraframe transparency, deals with questioning definitions of, for example, 'cleanliness' - can nuclear power be defined as a form of clean energy because it does not pollute in the way that coal-based electricity does? Interframe transparency takes the process of examination yet a step further, questioning frames themselves, and asking 'Are we posing the right questions?' and 'Are we moving in the right direction?' Thus this level of transparency reflects on the value and goals of the transparency process itself.

Klintman and Boström point out that the basis of their distinctions is the understanding that transparency requires a broad analysis, which takes into account political and cultural contexts: 'several debates presuppose these other layers of transparency: where procedural and political aspects of labelling schemes are acknowledged, where inconsistencies with the frames surrounding labelling schemes are identified, and even where the interpretive frames themselves are questioned'. These levels of questioning, common to transparency devices in general, shed light on the different areas of contestation in procedures that ostensibly lead to greater transparency for the public.

\section{TRANSPARENCY AND THE PUBLIC: PARTICIPATION, EXCLUSION, AMBIVALENCE}

Part III of this volume takes up transparency in processes that deal directly with the public, presenting three case studies where the 'carrying out of transparency' became quite difficult. These cases demonstrate that the public and the authorities that govern or organize them can have very divergent views as to what transparency consists of, and they also show how complex and sensitive negotiations can become. It is becoming more and more common for public authorities to try to involve, or to consult with the public in decision-making processes that are contested; yet increasingly authorities also find that they have their hands tied, be it by international agreements, economic factors or political pressures and considerations, and thus cannot follow through on the intention of the original plans. The lack of a clear idea of what, exactly, is possible and desirable, and a concrete 'design' for transparent procedures can also be a part of failures. Also, both public and state demands for transparency can be used as a weapon, to harass certain groups or to stop or hinder political process or decisions from being taken. 
Abram and Soneryd (Chapters 10 and 11) discuss case studies of particular fora for public participation, a practice that is gaining in popularity and is seen as a mechanism leading to greater transparency between the public and policy-makers. Abram's case comes from the field of urban renewal, or 'regeneration' in Britain, and analyses Norfolk Park, one such regeneration programme undertaken in Sheffield. The public was invited to participate in the planning of the project from the very beginning, and voiced particular requests, primarily regarding the building plan for the project and ecological solutions for the area. These were, however, gradually 'edited out' of the project, ostensibly for economic reasons - pointing at a fundamental problem in integrating the public in planning. Abram notes that there is an intrinsic incompatibility built into alliances such as the public-private partnerships now frequently used in redevelopment because the citizens that become involved (and sometimes planners) tend to seek solutions that are more oriented around social values than the profit values sought by implementers. When Norfolk Park inhabitants did not see any of their requests materialize, and received no good explanation for this, or for the lengthy delays, they tended to resort to explanations that involved corruption, or the individual prestige of the project implementers.

Yet another intrinsic problem is that of the definition of 'the public'. While elected representatives answer to a particular constituency, participative outcomes can depend highly on who comes to participate, and who stays away from open public meetings. The ways in which meetings are run, and how people are received are also likely to play a major role in outcomes, and there may well be need of a 'best practice' guideline for such attempts at public integration. In Sheffield, the many actors involved in the process contractors, subcontractors, the city council, special planning team and the 'landlord' (North British Housing) as well as different citizens' groups made transparency very difficult to achieve, and information about and explanations for delays, as well as the reasoning behind the plan that was executed, were not available to citizens, who seem to have been primarily sought in an early 'input' stage. Such attempts at integration through the practice of transparency are more likely to further alienate the public than encourage them to make contributions of time and energy. ${ }^{5}$ Thus, the manner in which 'the public' is to be involved in policy-making and local change becomes highly charged, and may not necessarily lead to greater transparency; it may, as in the case of Abram's participants, leave them feeling that the entire process in which they have participated is highly opaque and confusing.

This is an issue which also appears in Soneryd's discussion of a transparency forum held in Sweden to provide understanding of different stakeholders' concerns regarding the emissions from the third-generation (3G) 
telephony network under construction. Although Sweden's policy on emissions is in fact primarily driven by recommendations from international bodies such as the European Union and World Health Organization, the forum provided a way for groups to negotiate their positions in relation to each other, by testing 'articulations' or 'propositions' (Latour, 2004, p. 210f) of how things are, or could be, within a particular scientific/public arena. These propositions later become more formalized upon the production of a written report on the proceedings, leading to contestation over the editing of this report. Soneryd further shows how difficult it can be to arrange such a forum on a highly controversial issue, as the very setting up of the meetings, attendees and definitions of what is to be discussed also become processes of negotiation.

Viktorin (Chapter 12) brings up the challenges of transparency in the context of Viking 03, an international civil-military exercise carried out with the aim of developing technology and procedures useful when preparing troops for peace support missions. Improving civil-military co-operation was a large part of the exercise, as international security has increasingly become based on co-operation and openness - and here, transparency becomes a key concept. As an observer within the exercise evaluation group, Viktorin gained access to the discussions held prior to and after the exercise, as well as to the exercise itself. He notes the illusory distance between policy and audit: audit can be, and often is, designed to confirm the success or good performance of the institutions it is supposed to scrutinize. Everything depends on the questions asked, who is asking and who is answering. The independence of the auditors, as well as the audited, is thus crucial, and both parts need to be drawn from diverse backgrounds, as well as be free of the various pressures and influences that might be exerted on them. Simply creating such a situation can be an enormous challenge, even assuming the political will to create it exists. In Viking 03, evaluation and audit tended to merge, with an ulterior motive for the evaluation, and the means of achieving it, well established before the exercise began. As pointed out by Shore and Wright (1997, p. 62) 'challenging the terms of reference is not an option' in relation to a number of the concepts that we live by today - conflict preventionism is as taken for granted as neoliberalism and, indeed, as the idea of transparency itself.

Elections, and the presidential referendum that took place in Venezuela in 2004 is the subject of Montoya's chapter (Chapter 13). It points out that calls for transparency can also be used as a weapon to subvert democracy, which also requires hidden or opaque places in order to function. In the drawn-out battle against the presidency of Hugo Chávez, the many demands put on the opposition by the national electoral council in the interests of transparency obliged the opposition to collect signatures requesting 
a referendum over and over again. The draconian circumstances imposed on signature-collection led to a highly polarized political situation and the web publication of the list of signatories by a member of the legislature resulted in political persecution. When the referendum finally took place, the lack of transparency in the audit led to accusations of fraud, and the final failure of the vote to bring the referendum battle to a satisfactory closure. It put the entire electoral system in question, and when electronic fingerprint machines tested for subsequent elections proved to register the votes of participants, the opposition boycotted the vote, resulting in massive electoral abstention. Here, both transparency and non-transparency are being manipulated for political ends, putting faith in the electoral system and democratic practice in peril.

Transparency has come to be viewed as an important means for organizations and individuals to cleanse themselves of mistrust and accusations of various kinds. We may even say that there is now a generally held belief and trust in the notion of transparency as a response to drastic social change, brought about by the globalization of markets and an increasingly fragmented political authority. Facilitating communication and providing a point of direction among and for parties that may represent very different interests, the concept has the capacity to move across organizational, social and political contexts, to disentangle itself from the particularities of local context and to re-entangle with new actors in new contexts and situations. Its very abstractness and visionary character facilitates its use across social contexts, across organizations, countries and cultural boundaries of any sort. Transparency works across the board, so to speak. The desire to unveil the hidden, to disclose the closed, to reveal the concealed - in short to make transparent that which is out of sight - is as central to economic processes as it is to political ones (cf. Larsson and Lundberg, 1998). It evokes the idea that neither the organization, nor its members, have anything to hide. The concept may then work as a generalized motivational force with the capacity to influence and mobilize people in certain ways.

In this volume, we do not venture to provide the full picture of transparency as an organizational ideal. That would be an oxymoron, not least given the nature of the topic itself! Rather, our more modest hope is that the discussions in the chapters, separately and taken together, will inspire further reflection on what transparency is and may be in a given context, and what the call for transparency stands for. We believe that the answer to such questions orbits around classical questions of who we aspire to be, what missions we have for our organizations, and what hopes we hold for our societies. Transparency, in whatever mould it comes, provides a dramaturgy for organizational processes, and a direction for human beings. Whether it is an unquestioned good or not, we leave you to judge. 


\section{NOTES}

1. We may note here that philosophers like Merleau-Ponty $(1968 ; 1986)$ took an interest in the role of vision for the development of human consciousness and identity. For Merleau-Ponty (whose phenomenological view was influenced by that of Heidegger), when the child is capable of becoming a spectator of him or herself, as in a mirror, when he or she understands that he or she is visible to him or herself and others, the child is able to perceive him or herself as a bodily subject, and hence to engage with the world around him or her. (See also Lacan, 1977, for a similar philosophical standpoint regarding the 'mirror-stage' in personal development.)

2. Also in fiction writing and film, the links between transparency and the exercise of totalitarian power have been explored, perhaps most notably in George Orwell's Nineteen Eighty-Four (1949), and in The Traveler, by John Twelve Hawks (2005). A couple of films in which allusions to transparency are central are Irwin Winkler's The Net (Columbia TriStar, 1995) and Paul Verhoeven's Total Recall (Live/Artisan, 1990).

3. For a more recent printing, see Bentham (1995).

4. The literature on Foucault's analysis of power is vast. For an interesting discussion on the analysis of panopticon, see the interview 'The eye of power' (in Gordon, 1981). For further discussions on the relevance of the idea of panopticon in social science, see, for example, Roy Boyne (2000).

5. Writing about public policy in 'tenant management' schemes in England, Hyatt (2000) has also pointed out the large amounts of unpaid labour that is often required of poor people, often women, when they are required to become involved in participative schemes in the context of urban regeneration.

\section{REFERENCES}

Barthes, Roland (1967), Le Bruissement de la Langue, Paris: Editions du Seuil.

Barthes, Roland (1986), The Rustle of Language, New York: Hill and Wang.

Bauman, Zygmunt (1998), Globalization: The Human Condition, New York: Columbia University Press.

Bentham, Jeremy (1995), 'Panopticon', in Miran Bozovic (ed.), The Panopticon Writings, London: Verso.

Boyne, Roy (2000), 'Post-panopticism', Economy and Society, 29 (2), 285-307.

Deleuze, Gilles (1995), 'Postscript on control societies', in Gilles Deleuze, Negotiations, trans. M. Joughlin, New York: Columbia University Press, pp. 177-82.

Florini, Ann (2003), The Coming Democracy. New Rules for Running a New World, Washington, DC: Island Press.

Foucault, Michel (1977), Discipline and Punish: The Birth of the Prison, trans. Alan Sheridan, New York: Pantheon Books.

Giddens, Anthony (1990), The Consequences of Modernity, Cambridge: Polity Press.

Gordon, Colin (ed.) (1981), Michel Foucault, Power/Knowledge: Selected Interviews and Other Writings, 1972-1977, New York: Random House.

Graeber, David (2001), Toward an Anthropological Theory of Value: The False Coin of Our Own Dreams, Basingstoke: Palgrave.

Hawkes, John Twelve (2005), The Traveler, New York: Doubleday.

Heidegger, Martin (1982), The Basic Problems of Phenomenology, Bloomington, IN: Indiana University Press. 
Hood, Christopher (2007 [2006]), 'Transparency in historical perspective', in Christopher Hood and David Heald (eds), Transparency: The Key to Better Governance?, Oxford: Oxford University Press, pp. 3-23.

Hood, Christopher and David Heald (eds) (2007 [2006]), Transparency: The Key to Better Governance?, Oxford: Oxford University Press.

Hyatt, Susan Brin (2000), 'Poverty in a "post-welfare" landscape: tenant management policies, self-governance and the democratization of knowledge in Great Britain', in Cris Shore and Susan Wright (eds), The Anthropology of Policy: Critical Perspectives on Governance and Power, London and New York: Routledge, pp. 217-38.

Lacan, Jacques (1977), The Mirror Stage as Formative of the Function of the I as Revealed in Psychoanalytic Theory (first published 1949), in Ecrits: A Selection, trans. Alan Sheridan, London: Tavistock Publications.

Larsson, Mats and David Lundberg (1998), The Transparent Market, London: Macmillan.

Latour, Bruno (2004), 'How to talk about the body? The normative dimension of science studies', Body \& Society, 10 (2-3), 205-29.

Levin, David Michael (1988), The Opening of Vision: Nihilism and the Postmodern Situation, London: Routledge.

MacKenzie, Donald, David Hatherly and David Leung (2005), The Finitist Accountant: Classifications, Rules and the Construction of Profits, University of Edinburgh: Working Paper, School of Social and Political Studies.

Merleau-Ponty, Maurice (1968), The Visible and the Invisible, trans. Alphonso Lingis, Evanston, IL: Northwestern University Press.

Merleau-Ponty, Maurice (1986), Phenomenology of Perception, London: Routledge and Kegan Paul.

Miller, Peter (2001), 'Governing by numbers: why calculative practices matter', Social Research, 68 (2), 379-95.

Orwell, George (1949), Nineteen Eighty-Four, London: Secker and Warburg.

Porter, Theodore M. (1995), Trust in Numbers: The Invention of Objectivity, Princeton, NJ: Princeton University Press.

Power, Michael (1997), The Audit Society: Rituals of Verification, Oxford: Oxford University Press.

Rose, Nikolas (1999), Powers of Freedom: Reframing Political Thought, Cambridge: Cambridge University Press.

Scott, James C. (1998), Seeing Like a State: How Certain Schemes to Improve the Human Condition Have Failed, New Haven, CT: Yale University Press.

Shore, Cris and Susan Wright (eds) (1997), The Anthropology of Policy, London: Routledge.

Strathern, Marilyn (2000), 'The tyranny of transparency', British Educational Research Journal, 26 (3), 309-21.

Strathern, Marilyn (2005), 'Robust knowledge and fragile futures', in Aihwa Ong and Stephen J. Collier (eds), Global Assemblages: Technology, Politics and Ethics as Anthropological Problems, Malden, MA and Oxford: Blackwell, pp. 464-81.

West, Harry G. and Todd Sanders (eds) (2003), Transparency and Conspiracy: Ethnographies of Suspicion in the New World Order, Durham, NC: Duke University Press. 
Christina Garsten and Monica Lindh de Montoya - 9781848441354 Downloaded from PubFactory at 04/26/2023 02:49:54PM 